7. Anhang zur Arbeit von Hrn. F. Paschen über ,Die Seriensysteme in den Speletren von Zink, Cadmium und Quecksilber"; von T. Royds.

Paschen vermutet, $\mathrm{da} B$ die einfachen Linien einiger Serien einen normalen Zeemaneffekt zeigen. Den Zeemaneffekt einiger dieser Linien habe ich jetzt gemessen. Es ist nur gelungen bei den Linien $6438,71(\mathrm{Cd})$ und $6362,58(\mathrm{Zn})$, denn die anderen Linien sind in dem Funken zu schwach und unscharf. Die Aufspaltung der Magnesiumlinien 5528,75 und 4703,33 ist nach einer verstärkten Platte gemessen, welche herrührt von der Arbeit von Runge und Paschen. Doch waren auch diese Linien sehr unscharf und schwach. $\mathrm{Zu}$ gleich mit 6438,7 und 6362,6 , erschienen die Tripletlinien von $\mathrm{Zn}$ und $\mathrm{Cd}$ und die Natriumlinien auf der Platte. Aus ihrer Aufspaltung wurde unter Annahme der Gesetze von Runge und der Messung von $\left.\mathrm{Gmelin}^{1}\right)$, das Feld berechnet. Die Linien 6438,7 (Cd), 6362,6 (Zn), 5528,7 (Mg), 4703,3 (Mg) erschienen im magnetischen Felde als symmetrische Triplets, und die folgenden Messungsresultate entsprechen innerhalb ihrer Genauigkeit dem Kathodenstrahlwerte von $e / m=1,77 \times 10^{7}$. Die Werte von $\delta \lambda / \lambda^{2}$ sind von der mittleren Komponente an gerechnet.

\begin{tabular}{c|c|c|c|c}
\hline \hline & $\lambda$ & $\delta \lambda / \lambda^{2}$ & $H$ & $e / m$ \\
$\mathrm{Cd}$ & 6438,7 & 1,405 & 30000 & $1,76 \times 10^{7}$ \\
$\mathrm{Zn}$ & $\mathbf{6 3 6 2 , 6}$ & 1,420 & 30000 & 1,77 \\
$\mathrm{Mg}$ & 5528,7 & 1,37 & 30000 & 1,72 \\
$\mathrm{Mg}$ & 4703,3 & 1,33 & 30000 & 1,67 \\
$\mathrm{Hg}$ & 4916 & $\left.\frac{2,19}{2}{ }^{2}\right)$ & 23010 & 1,78 \\
$\mathrm{Hg}$ & 4108 & $\left.\frac{1,99}{2}{ }^{2}\right)$ & 23010 & 1,62
\end{tabular}

1) P. Gmelin, Ann. d. Phys. 28. p. 1079. 1909.

2) Nach Runge und Paschen.

(Eingegangen 23. November 1909). 


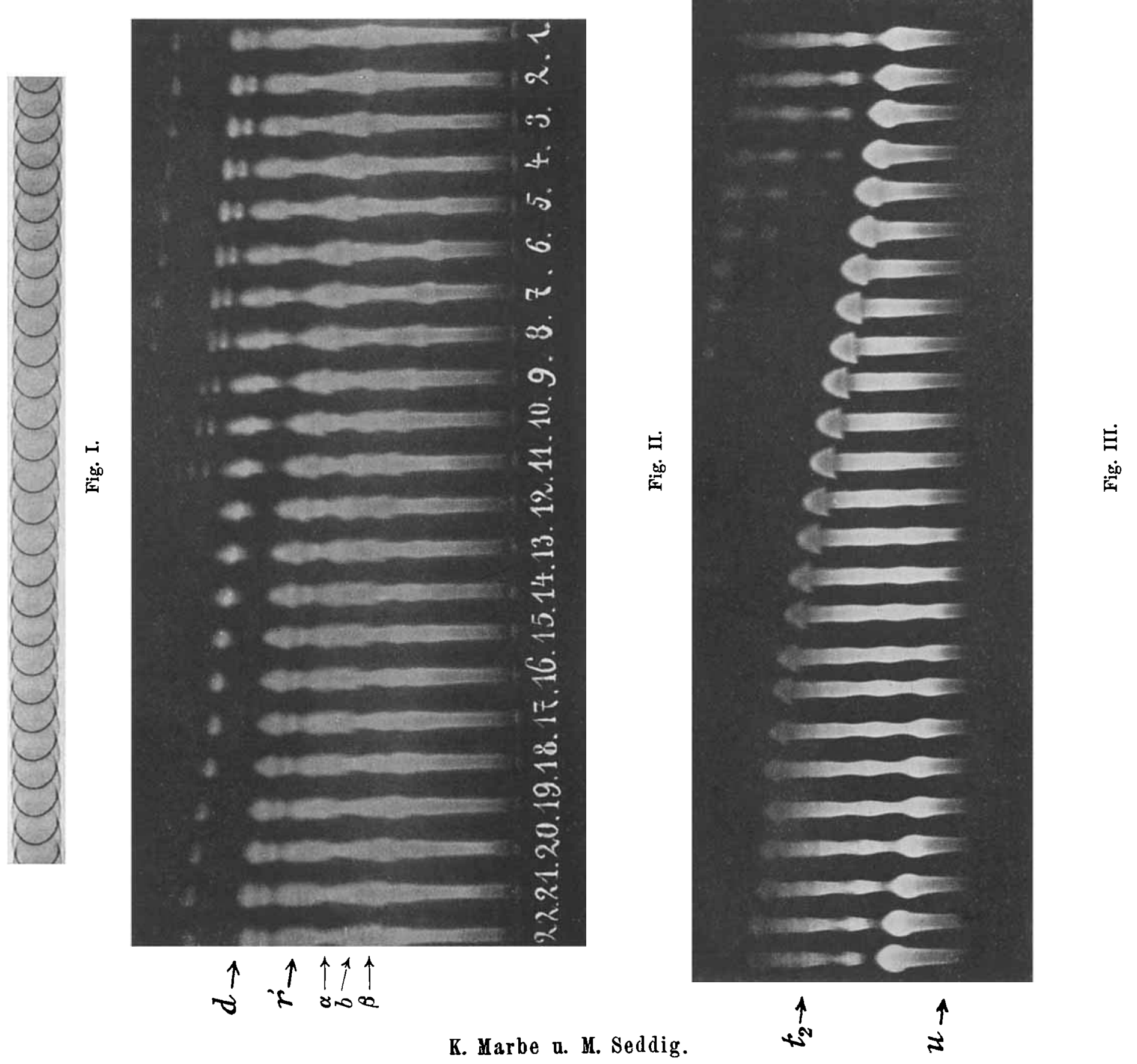




\section{Queeksilberlampe; Entwickelungspapier.}

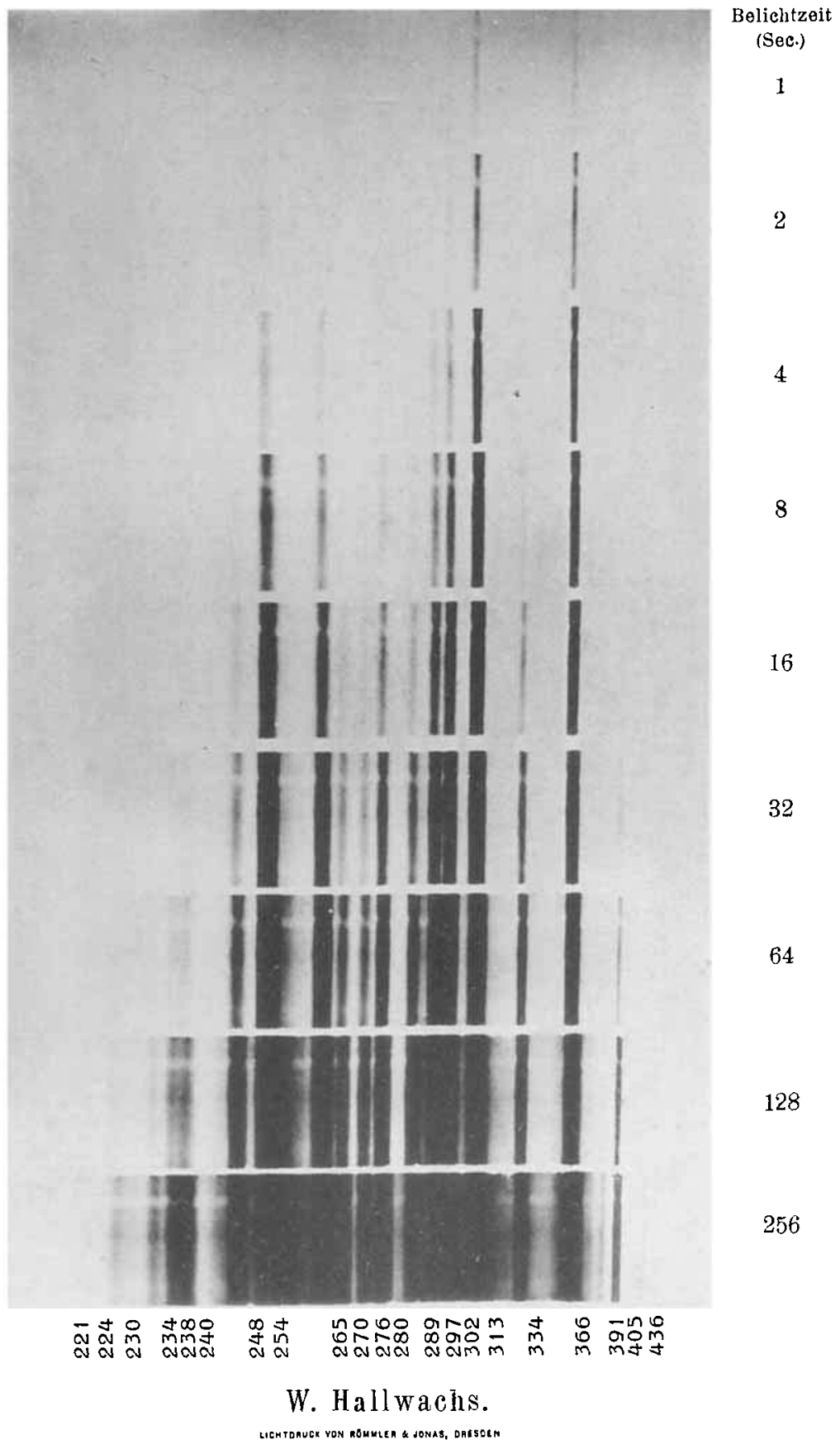



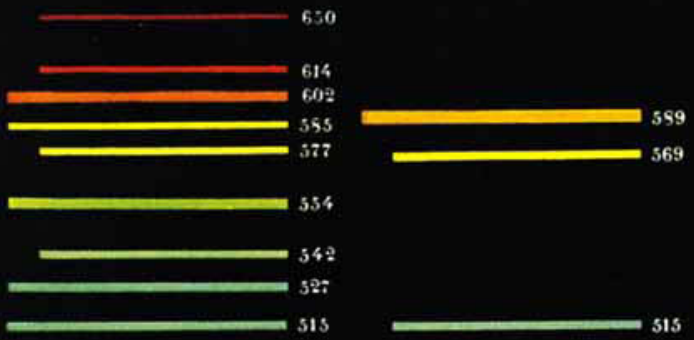
Versuch Nr. 3.

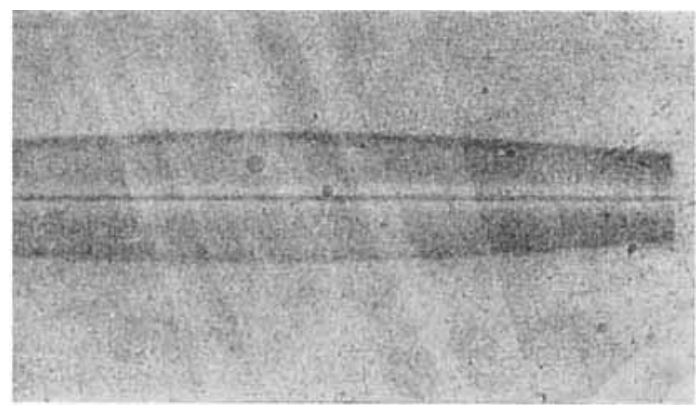

Fig. 1 a.

Fig. 1 b.

A. H. Bucherer. 